\title{
Discussion About the development of Power Transmission Line in China
}

\section{with advice}

\author{
Lai $\operatorname{Dian}^{1, a}$
}

${ }^{1}$ North China Electric Power University, 071006

\begin{abstract}
KeyWords: Power Transmission Lines, Ultra High Voltage, Intelligent, Advice
\end{abstract}
\begin{abstract}
With the vigorous advance of power transmission lines,the development and construction ofpower transmission lines directly affects the development of Chinese power grid and the construction of electricity economy.Therefore,as is shown in this paper,it has an depth discuss and research in the development prospect of China's power transmission lines,ultra high voltage power transmission lines and intelligent development of power transmission lines,then put forward some guidance advice.
\end{abstract}

\section{Introduction}

With the rapid development and progress of society and economy,people's standard of living have improved,also calls for the corresponding improvement and innovation of various infrastructure, in order to meet the increasingly demanding requirements of people.The transmission line engineeringrelates directly to our life and production, which is also the basis of social economic development and the safeguard. And with the science and technology constantly develop in the direction of intelligent and ultra high voltage, the application of intelligent technology and high voltage transmission technology in power transmission lines has become the emphasis of the future development ${ }^{[1-2]}$.

\section{The present status of power transmission lines' construction in the 21st century in China}

Nearly 50 years,Chinese power transmission lines' construction achievement is enormous. The total length of line developed from $6500 \mathrm{~km}$ into $65656 \mathrm{~km}$ from 1949 to 1996.In the 1950s,we constructed a large number of power transmission lines in $35 \mathrm{kV}$ and $110 \mathrm{kV}$; in the 1960 s, many cities built the $220 \mathrm{kV}$ line, and gradually formed regional $220 \mathrm{kV}$ power grid ${ }^{[3]}$.As the growth of the power load and the development of large water, fire power, in 1972 we built the first 330 kVultra high voltage lines in Liujiaxia hydropower station which is total length of $534 \mathrm{~km}$. Afterwards, the $330 \mathrm{kV}$ line extended to the Shanxi,Gansu,Ningxia,Qinghai 4 provinces and municipalities to form the northwest provinces combined grid.In 1981 the first $500 \mathrm{kV}$ line was put into operation, total length of $595 \mathrm{~km}$ from Pingdingshan to Wuhan then other areas that have adopted $500 \mathrm{kV}$ voltage level.Now across the country had northeast, north China, east China, central China, northwest, south and Chuanyu seven Inter-provincial power grid and Shandong, Fujian, Hainan, Tibet, Xinjiang five provinces (area) independently network.Network with a total of $220 \mathrm{kV}$ line which length 120000 km, 330 kV line which length 7500 km, 500 kV line which length $20000 \mathrm{~km}$. Between central China and east China power grid, interconnection by $1500 \mathrm{kV}$ line from Gezhouba to Shanghai. China's construction scale and growth speed of the power transmission line is rarely fast in the world. China is a large country, and regional geology, topography, meteorology 
and other natural environment is more complex. Lots of technical problems have appeared during the construction. Through a large number of engineering practice, we has accumulated abundant experiences in designing, constructing and operating of the power transmission lines' in mountain areas, serious ice region, typhoon, high altitude, poor geological areas, earthquake disaster areas and so on.In addition, the power transmission lines across the big rivers, lakes and the straits and other waters across the engineering design, construction and operation has also made great achievements. China has stronger power of power transmission lines survey, design, construction and operation management of power, and with the required equipment and transmission line equipment manufacturing capacity. Besides, the research of transmission lines, testing institutions and facilities have made a large number of test results of scientific research, and have created favorable conditions for the further development of ultrahigh voltage and large capacity transmission lines.

\section{The development and suggestions of ultra high voltage power transmission lines}

Ultra high voltage power grid in our state grid is the monster power grid that consists of ultra high voltage backbone network frame including $1000 \mathrm{kV}$ AC transmission system and above $600 \mathrm{kV}$ DC transmission network. Since 1960, the research and application of ultra high voltage start extensively developed in different parts of the globe, upsurging a wind in the research of ultra high voltage power grid. Along with our country coming into the primary stage of socialism, China's economic development and unceasing expansion of industrial scale, the accompanying trouble is the rising of power load. It is necessary to use the new result of ultra high voltage transmission lines to reduce the loss of transmission lines on the long-distance transmission, improve the phenomenon of excessive transmission losses in the past and save electricity. Now the typical representation of ultra high voltage AC transmission lines system which has put into operation is the line of north Shanxi - southwest Shanxi - Nanyang - Jingmen. At first, the fault current level of power transmission lines in this system was low. It's not strong enough forthe four parts ofthe transmission lines contact ${ }^{[4]}$.

Here are our suggestions to the ultra high voltage power transmission lines in China in the following aspects:

(1) DC transmission overvoltage's protection. About ultra high voltage DC transmission lines system, the problem we need to pay special attention to is that DC overvoltage in the field. Extra high voltage over-voltage protection is mainly to protect operating overvoltage and the overvoltage protection caused by lightning. In the insulation system, the nature of air insulation properties of ultra high voltage are quite different from high pressure air insulation. And insulation system in ultra high voltage system mainly associates with overvoltage protection. We should control the overvoltage by a certain technology, ensuring good properties of high voltage insulation system and improving the stability and security of the ultra high voltage power transmission lines system.

(2) The ultra high voltage power transmission lines system and the natural environment. To establish a certain scale of ultra high voltage power transmission lines, we must consider the problem of environmental pollution which caused by them. We should obey the relevant state laws and regulations of environmental protection, reasonably construct the ultra high voltage power transmission lines system, and realize the sustainable development of the ultra high voltage power transmission lines system.

(3) The unity standard of ultra high voltage power transmission lines system. At present, the experience of ultra high voltage power project is not enough for our country. There is no standard can be widely used. Thus we need to establish a set of stable and science of the ultra high voltage power transmission system through theestablishment of the field of engineering in a planned way. 


\section{The development and suggestions of intelligence power transmission lines}

So-called intelligent power transmission lines refers to the use of advanced control technology, information technology, modern communication technology and so on to realize automation and digitalization of the power transmission lines operation, control them intelligently, and ensure its smooth functioning. Considering the present stage of development of intelligent power transmission lines in our country, the overall is in the initial stage of development. Although at present many international advanced production technology and science and technology are gradually applied to the whole development process, there are still many problems in the power transmission lines in the process of the development of intelligence, which need further development and perfection.

Through the related literature review of ${ }^{[5-6]}$, this article analyzes the development direction of intelligent power transmission lines in several aspects:

Geographic information system. Use the application of navigation technology, radar, remote sensing technology to be the support of geographic information system technology, complete the intelligent model to the transmission line and the environment, and build a 2D or 3D model of the power transmission line. However, in the process of the application of this technology, due to the influence of image resolution level, the corresponding capital investment in the process of using is high. We need further research to reduce costs, which can gradually spread to the intelligent application of power transmission lines.

The helicopter intelligent inspection system. With the continuous development of economy, our comprehensive national strength and international competitiveness have been significantly improved. The accelerating process of urbanization and people's basic needs are not short, especially for the electric power. Every corner of people's life needs supports of power resources. Power transmission system and power grid have begun to much more widely distribute in every corner of our country. But there are still a lot of people less area, even no-human land transmission network cannot be a good guarantee for its regulation. The artificial management can no longer be good to meet the needs of this region. These cause the emergence and development of the helicopter intelligent inspection system. But as for the helicopter intelligent inspection system of the whole development of our country, its application is not widespread and common because the cost is too high. And at the same time, the helicopter intelligent inspection system in the process of work to the requirement of the weather has a very strong demand, especially in the detection of the growing regional power transmission network. Therefore, the present stage helicopter intelligent inspection system in our country cannot completely replace manual inspection system, it still needs to continue to improve and develop.

The intelligent robot inspection system. China's land area is nine hundred and sixty square kilometers, which is the world's third largest country. The vast territory and abundant resources cause the power transmission lines travel around the every corners of the country. A large number of power transmission lines need a lot of manual patrol and inspection. These have all brought the very big working pressure to the related department. So it is very necessary to work on introducing modern intelligent robot inspection system. It's also an inevitable trend of era development. At present, in the process of power transmission line inspection in our country, we mainly rely on visible light cameras and infrared electronic detectors two components. Intelligent robots comply with these two commands to work and pass thecollected information to the central processor with a timely manner. Then the CPU analyzes data and solve problems in the timely manner. But according to the current situation in the general characteristics of the intelligent inspection system, we are still suffering from some restrictions in terms of the money, environment, and weather. It's hard to comprehensive on the promotion. 
(4) The intelligent unmanned checking system. In recent period, intelligent unmanned inspection gradually develop and perfect, its technology has also made some breakthrough. The intelligent unmanned checking system works on the basis of the remote control. It checks the machine trajectory control with job content and it can easily complete the remote monitoring and control of transmission lines, which has a big difference to the previous artificial inspection. It can reach some person-cannot-reach area and make the whole staff in the process of inspection guarantee the security. In addition, because the intelligent unmanned checking system has a very high level of technology, the monitoring data also has very high precision. However, due to the intelligent unmanned checking system is still in its primary stage, the lack of practical application in the popularization and application of gradually should be further improved.

\section{Conclusion}

With the promotion of ultra high voltage technology and the project of smart grid, the power transmission engineering construction of China should search and develop a security, economic and practical scientific achievements. It will thoroughly change the conservative and backward status of the basic design of power transmission lines in China and create a "advanced technology, design reasonable and safety" situation 21 century power transmission line foundation engineering in our country.

\section{Reference}

[1] Cui Peng, Wang Bin.Power transmission lines’ relay protection research and development trend analysis [J].Agricultural Science\&Technology and Equipment,2016,(8):83-84.

[2] Huang Zhiming.Development prospects in the 21st century of China's powertransmissionlines[J].InternationalElectricPowerFor China,2000,(3):29-33.

[3] Chai Xiaoliang,LiHaixuan,WuHanbin.The construction planning and development analysis of the power transmission lines [J].Electronics World,2012,(22):53.

[4] Xiao Dongming, Wang Jing. Intelligent power transmission lines' directionanalysis[J].ChinaElectricPower Education, 2012,(27):138-139.

[5]Ma Huan,ZhouXiaofeng.New development of power transmission lines’ running[J].Technology Wind,2010,(23):216.

[6] Wen Ligang,SongXiaoguang. The development ofintelligent power transmissionlines'[J].China High Technology Enterprises ,2015,(26):121-122. 